\title{
Analysis of Photomutagenicity of Thiabendazole with UVA Irradiation: Absence of 8-Hydroxyguanosine Formation
}

\author{
Mie Watanabe-Akanuma ${ }^{1,3}$, Yohei Inaba ${ }^{2}$ and Toshihiro Ohta ${ }^{2}$ \\ ${ }^{1}$ Biomedical Research Laboratories, Kureha Co., Tokyo, Japan \\ ${ }^{2}$ Tokyo University of Pharmacy and Life Science, Tokyo, Japan
}

(Received May 16, 2006; Revised June 19, 2006; Accepted June 20, 2006)

\begin{abstract}
We recently reported the photomutagenic property of thiabendazole [2-(4-thiazolyl)-1H-benzimidazole, TBZ], a post harvest fungicide, in bacterial and mammalian cells. In the present study we investigated its photomutagenic potential along with several of its structurally-related pesticides including benomyl, mefenacet, tricyclazole, and imazalil. None of the compounds except TBZ showed photomutagenicity with UVA-irradiation in S. typhimurium TA100, TA98, or E. coli WP2uvrA/pKM101. Since TBZ consists of thiazole and benzimidazole rings, we then investigated photomutagenic potential of thiazole, benzimidazole, and 2-phenylbenzimidazole. Only 2-phenylbenzimidazole showed very weak photomutagenicity with UVA-irradiation. These results indicate both benzimidazole ring and thiazole ring are necessary for UVA-activation of TBZ. We measured 8-hydroxydeoxyguanosine (8-OHdG) in salmon sperm DNA exposed to TBZ and UVA by HPLC-ECD, and found that $8-0 H d G$ was not responsible for the photomutagenesis of TBZ.
\end{abstract}

Key words: photomutagenicity, UVA, TBZ, pesticide, 8-OHdG

\section{Introduction}

Thiabendazole [2-(4-thiazolyl)-1 $H$-benzimidazole, TBZ] is approved in Japan as a post-harvest fungicide for imported citrus fruits during transport and storage. We previously reported that TBZ shows potent photomutagenicity following UVA irradiation (320-400 $\mathrm{nm}$ ) for $10 \mathrm{~min}$ at a dose rate of $2.5 \mathrm{~J} / \mathrm{m}^{2} / \mathrm{sec}$ in Escherichia coli strain WP2uvrA/pKM101 and $S$. typhimurium strains TA97, TA104, and TA100 (1-3). Structurally related compounds containing imidazole or thiazole, such as benomyl, mefenacet, tricyclazole, and imazalil are widely used in agriculture as pesticides. The first purpose of the present study was to investigate whether those compounds are also photomutagenic.

TBZ photomutagenicity is observed when bacterial cells are irradiated with UVA in its presence, but neither pre-irradiation of TBZ just before adding the cells, nor pre-treatment of cells with TBZ before UVA-irradiation generates mutagenicity $(1,3)$. It seems likely, therefore, that the photomutagenic TBZ products are unstable and/or rapidly react with other molecules before being incorporated into the cells. One likely mutagenic species could be oxygen radicals. The contribution of reactive oxygen species to photomutagenicity has been reported for many chemicals, including methylene blue (4), chlorpromazine $(5,6)$, benzo[a]pyrene $(7)$, and several $N$-nitroso compounds (8-11). The second purpose of the present study was to investigate the possibility that 8-hydroxydeoxyguanosine $(8-\mathrm{OHdG})$ is formed in DNA exposed to TBZ and UVA in vitro.

\section{Materials and Methods}

Chemicals, bacterial strains and media: Thiabendazole [2-(4-thiazolyl)-1 $H$-benzimidazole, TBZ, CAS No. 148-79-8], benomyl [methyl 1-(butylcarbamoyl)-2benzimidazolecarbamate, CAS No. 17804-35-2], mefenacet (2-benzothiazol-2-yloxy- $N$-methylacetanulide, CAS No. 73250-68-7), tricyclazole (5-methyl-1,2,4triazolo[3,4- $b$ ]benzothiazole, CAS No. 41814-78-2), imazalil \{1-[2-(2,4-dichlorophenyl)-2-allyloxyethyl]-1 Himidazole, CAS No. 35554-44-0\}, benzimidazole (CAS No. 51-17-2), 2-phenylbenzimidazole (CAS No. 716-79-0), and thiazole (CAS No.288-47-1) were purchased from Wako Pure Chemical Industries Ltd., (Tokyo). Figure 1 shows the structures of these compounds. Angelicin (CAS No. 523-50-2) was obtained from Sigma-Aldrich Co., (MO, USA). Compounds were dissolved in dimethylsulfoxide (DMSO) just before the experiments. The final concentration of DMSO in cell suspension during UVA irradiation was $4 \%$ or less. We used S. typhimurium strains TA100 (hisG46, uvrB, rfa/pKM101), TA98 (hisD3052, uvrB, $r f a / \mathrm{pKM} 101)$, and $E$. coli strain WP2uvrA/pKM101 $[\operatorname{trpE65}, u v r A]$ for the reverse mutation assays and cultured them in Nutrient medium (Oxoid, No.2) at

${ }^{3}$ Correspondence to: Mie Watanabe-Akanuma, Kureha Co. Biomedical Research Laboratories, 3-26-2, Hyakunin-cho, Shinjuku, Tokyo 169-8503, Japan. Tel: +81-3-3362-7420, E-mail: akanuma@kureha. co.jp 

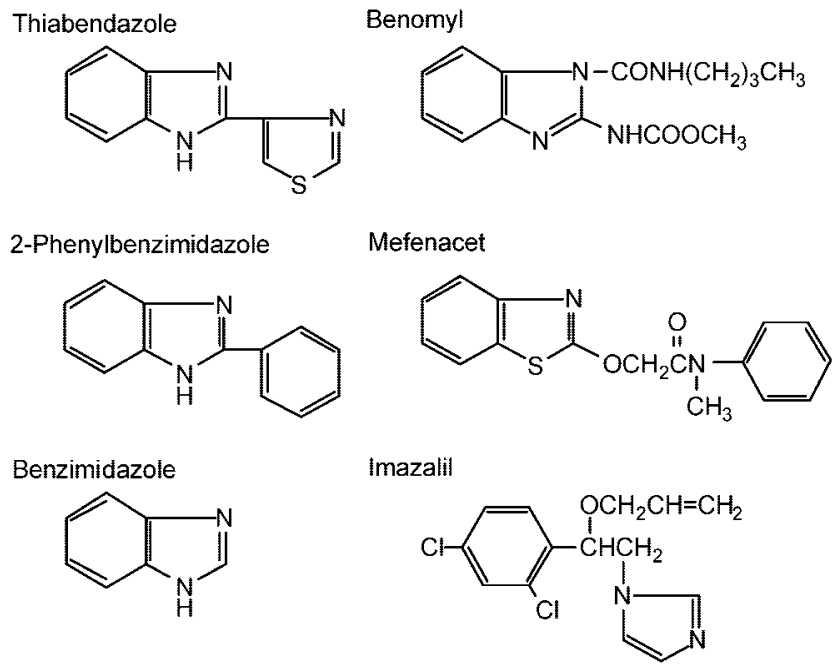

Thiazole<smiles>c1cscn1</smiles>

Tricyclazole

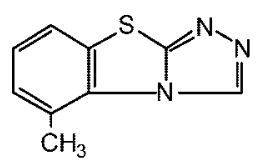

Fig. 1. Chemical structure of TBZ and its structurally-related compounds investigated.

$37^{\circ} \mathrm{C}$ with shaking. Minimal glucose agar plates consisted of Vogel-Bonner E medium supplemented with $2 \%$ glucose and $1.5 \%$ agar (12). Top agar $(0.6 \%$ agar and $0.5 \% \mathrm{NaCl}$ ) contained $0.05 \mathrm{mM}$ D-biotin and $0.05 \mathrm{mM}$ L-histidine for (S. typhimurium) or $0.05 \mathrm{mM}$ L-tryptophan (for E. coli).

UVA irradiation and reverse mutation assay: We used a black-light fluorescent lamp (National Black Light Blue, FL15BL-B, 15W, Matsushita Electric Industrial Co., Japan) that emitted wavelengths of $300-400 \mathrm{~nm}$ as the UVA source. To filter out UVB wavelengths below $320 \mathrm{~nm}$, we inserted a 5 -mm thick soft glass plate between the culture dishes and the lamp. UVA was irradiated from a distance of $20 \mathrm{~cm}$ at a dose rate of $2.5 \mathrm{~J} / \mathrm{m}^{2} / \mathrm{sec}$ (UVX Radiometer, Model UVX-36, Ultra-Violet Products, Upland, CA, USA) on a 24-well multiplate with lid. We placed $0.1 \mathrm{~mL}$ of overnight culture $\left(1-3 \times 10^{9}\right.$ cells $\left./ \mathrm{mL}\right)$ in each well of a 24-well multiplate containing $0.5 \mathrm{~mL} 100 \mathrm{mM}$ sodium phosphate buffer ( $\mathrm{pH} 7.4)$. We added the test compound solution $(5-20 \mu \mathrm{L})$ dissolved in DMSO, mixed it in well, and irradiated the mixture with UVA for $10 \mathrm{~min}$ at room temperature. We then added the mixture in each well to $2 \mathrm{~mL}$ molten top agar in a test tube kept at $46^{\circ} \mathrm{C}$, immediately poured the mixture onto a minimal glucose agar plate, incubate the plates for 2 days at $37^{\circ} \mathrm{C}$, and then counted the number of $\mathrm{His}^{+}$or $\mathrm{Trp}^{+}$revertant colonies. All experiments were conducted in duplicate, the controls in triplicate. We judged as positive a doubling or greater increase over the control value together with a dose-related response. Angelicin was used as a positive control for photomutagenicity (13).

8-OHdG assay: We dialyzed salmon spermary DNA (Wako Pure Chemical) dissolved in TE buffer at a concentration of $5 \mathrm{mg} / \mathrm{mL}$ against $10 \mathrm{mM}$ Na-phosphate buffer (pH7.4). TBZ was dissolved in methanol at a concentration of $10 \mathrm{mg} / \mathrm{mL}$. We mixed DNA $(0.5 \mathrm{mg})$ and TBZ (0.05 and $0.1 \mathrm{mg})$ into $0.25 \mathrm{~mL}$ sodium phosphate buffer in each well of a 24-well multiplate (final concentrations of TBZ were 2 and $4 \mathrm{mg} / \mathrm{mL}$ ). We used $N$-nitrosopyrrolidine (SigmaAldrich, CAS No. 930-55-2) dissolved in buffer as the positive control (10). We irradiated the mixture with UVA for 15, 30, and $60 \mathrm{~min}$ and then dialyzed the reaction mixture against water. We treated the dialyzed DNA with Nuclease P1 (5 unit, Seikagaku Corp., Tokyo) in sodium acetate buffer $(20 \mathrm{mM}, \mathrm{pH} 4.8)$ at $37^{\circ} \mathrm{C}$ for $2 \mathrm{~h}$, and then by bacterial alkaline phosphatase (1 unit, Takara Bio Inc., Shiga, Japan) in Tris- $\mathrm{HCl}$ buffer $(100 \mathrm{mM}, \mathrm{pH} 8.0)$ at $37^{\circ} \mathrm{C}$ for an additional $2 \mathrm{~h}$. We then removed the enzymes by ultrafiltration $(14,000$ $g, 10 \mathrm{~min}$ ) with Microcon YM-30 (Millipore Corp., USA), added $1 \mu \mathrm{L} 500 \mathrm{mM}$ EDTA (pH8.0) to the filtered samples, and kept the mixture at $-20^{\circ} \mathrm{C}$. We measured the amount of deoxyguanosine $(\mathrm{dG})$ and 8 hydroxy-2'-deoxyguanosine (8-OHdG) using a highperformance liquid chromatography (HPLC) system (Tosoh, Japan). The system was composed of two pumps (CCPM-II), a degasser (SD-8020), an autosampler (AS-8020), a column oven (CO-8020), a reversephase column (Hyderosphere $\mathrm{C} 18,5 \mu \mathrm{m}, 150 \times 4.6 \mathrm{~mm}$ ID, YMC, Japan), a UV detector (UV-8020), and an electrochemical detector (ECD, EC-8020). We used Tosoh HPLC Multi Station software (LC-8020) for data acquisition. A $25 \mu \mathrm{L}$ of sample was injected into the HPLC system. 8-OHdG and dG were eluted at a flow rate of $1 \mathrm{~mL} / \mathrm{min}$. We used two solvents for gradient elution-solvent A (2\% acetonitorile in $10 \mathrm{mM}$ phosphate buffer and $1 \mathrm{mM}$ EDTA, $\mathrm{pH}$ 7.0) and solvent $\mathrm{B}$ ( $8 \%$ acetonitrile in the same buffer). The elution conditions were as follows: $0-5 \mathrm{~min} 0 \%$ solvent $\mathrm{B} ; 5-20 \mathrm{~min}$, $0-100 \%$ solvent $\mathrm{B} ; 20-25 \mathrm{~min} 100 \%$ solvent B isocractic; $25-30$ min $100-0 \%$ solvent $\mathrm{B}$. The column temperature was maintained at $35^{\circ} \mathrm{C}$. $8-\mathrm{OHdG}$ was detected with the ECD equipped with glassy carbon working electrode operated at $+500 \mathrm{mV}$ versus an $\mathrm{Ag} / \mathrm{AgCl}$ reference electrode. $\mathrm{dG}$ was measured by $\mathrm{UV}$ absorption at $254 \mathrm{~nm}$. Data were expressed as $8-\mathrm{OHdG} / 10^{5} \mathrm{dG}$ (nM).

\section{Results and Discussion}

Table 1 shows the results of photomutagenicity test on pesticides with $E$. coli WP $2 u v r A / p K M 101$ and $S$. typhimurium TA100 and TA98. No mutagenicity was observed with benomyl, mefenacet, tricyclazole, or im- 
Table 1. Photomutagenicity of test pesticides

\begin{tabular}{|c|c|c|c|c|}
\hline \multirow{2}{*}{ Compound } & \multirow{2}{*}{$\begin{array}{c}\text { Dose } \\
\mu \mathrm{g} / \text { plate }\end{array}$} & \multicolumn{3}{|c|}{ Revertants/plate ${ }^{\dagger}$} \\
\hline & & WP2uvrA/pKM101 & TA100 & TA98 \\
\hline Solvent control & & 83 & 113 & 17 \\
\hline UVA control & & 94 & 107 & 19 \\
\hline \multirow{3}{*}{ TBZ } & 50 & 377 & 165 & 18 \\
\hline & 100 & 591 & 257 & 23 \\
\hline & 500 & 623 & 246 & 21 \\
\hline \multirow[t]{4}{*}{ Benomyl } & 10 & 90 & 105 & 14 \\
\hline & 50 & 84 & 94 & 18 \\
\hline & 100 & 64 & 71 & 11 \\
\hline & 500 & 28 & 33 & 4 \\
\hline \multirow{4}{*}{ Mefenacet } & 50 & 98 & 99 & 14 \\
\hline & 100 & 90 & 97 & 16 \\
\hline & 500 & 102 & 92 & 12 \\
\hline & 1000 & 98 & 102 & 14 \\
\hline \multirow[t]{4}{*}{ Tricyclazole } & 50 & 85 & 109 & 17 \\
\hline & 100 & 84 & 114 & 15 \\
\hline & 500 & 51 & 100 & 16 \\
\hline & 1000 & 28 & 67 & 13 \\
\hline \multirow[t]{5}{*}{ Imazalil } & 5 & 72 & 111 & 14 \\
\hline & 10 & 67 & 113 & 10 \\
\hline & 50 & 79 & 114 & 11 \\
\hline & 100 & 57 & 111 & 9 \\
\hline & 200 & $*$ & $*$ & $*$ \\
\hline Angelicin & 2 & 948 & 472 & 18 \\
\hline
\end{tabular}

${ }^{*}$ Growth inhibition, ${ }^{\dagger}$ Mean of duplicate plates.

Cells were irradiated with UVA for $10 \mathrm{~min}$ in the presence of the chemical.

azalil, while UVA-preirradiated TBZ induced reverse mutations in WP2uvrA/pKM101 and TA100. Since the photomutagenic property was dependent on the structure of TBZ, we then investigated photomutagenic potential of thiazole, benzimidazole, and 2-phenylbenzimidazole with WP2uvrA/pKM101. 2-Phenylbenzimidazole precipitated at doses of $100 \mu \mathrm{g}$ or more, which limited effective UVA-irradiation. Thiazole and benzimidazole could be tested up to a dose of $500 \mu \mathrm{g}$ without precipitation. Neither thiazole nor benzimidazole showed photomutagenicity with UVA-irradiation. On the other hand, the photomutagenicity of UVAirradiated 2-phenylbenzimidazole was marginal at a dose of $50 \mu \mathrm{g}$ (Fig. 2). The weak increase was reproducible in the four independent experiments (the maximum increase in each experiment was 2.4, 2.2, 1.9, and 2.0 times the control; data not shown). The limited activity of the compound might be due to its low solubility. On the other hand, 2-phenylbenzimidazole-5-sulfonic acid, a derivative of 2-phenylbenzimidazole, is widely used in sun-screen and cosmetics because of its strong absorption in the UVB region (14-17). Stevenson and Davies (17) reported that 2-phenylbenzimidazole and 2-phenylbenzimidazole-5-sulfonic acid caused guanine base damage in DNA by sensitizing photooxidation by singlet oxygen via both type I and type II mechanisms

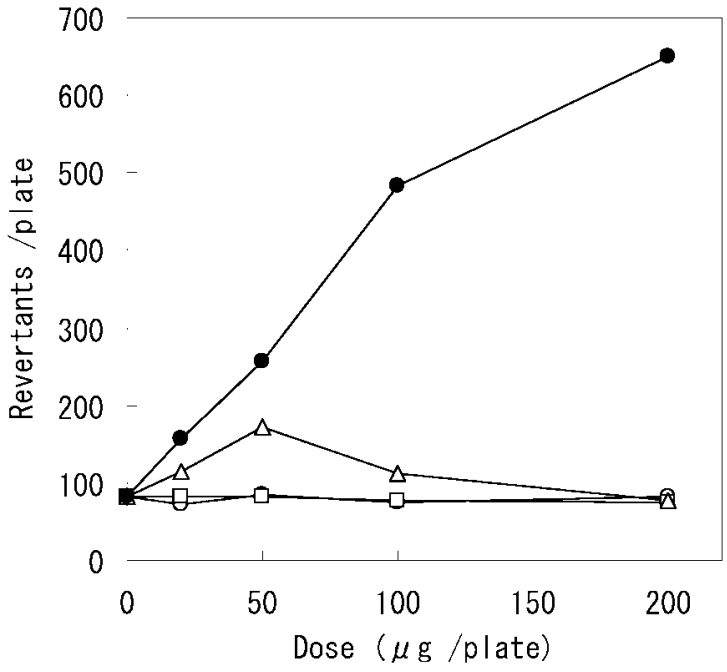

Fig. 2. Photomutagenic activity of $\mathrm{TBZ}$ and 2-phenylbenzimidazole with UVA-irradiation in E. coli WP2 $u v r A$ /pKM101. The mixture of bacterial cells and test compound in $0.5 \mathrm{~mL}$ of phosphate buffer was irradiated with UVA for $10 \mathrm{~min}$. Data are the means of 2 experiments. Benzimidazole (open circle); Thiazole (open square); 2-Phenylbenzimidazole (open triangle); TBZ (closed circle).

when they are exposed to narrow-band UVB radiation or natural sunlight. We, therefore, investigated photomutagenic potential of 2-phenylbenzimidazole-5sulfonic acid with UVA-irradiation using WP2uvrA/ pKM101 and TA100 at doses up to $200 \mu \mathrm{g} /$ plate. No photomutagenicity was detected with UVA-irradiated 2-phenylbenzimidazole-5-sulfonic acid (data not shown). These results indicate that both the benzimidazole ring and the thiazole ring are necessary for UVAactivation of TBZ.

In order to investigate the possible contribution of 8 -OHdG in photomutagenesis of TBZ, we assayed 8-OHdG formation in DNA exposed to TBZ and UVA in vitro. Salmon sperm DNA solution was irradiated with UVA for 15, 30, and $60 \mathrm{~min}$ in the presence of TBZ at 200 and $400 \mu \mathrm{g} / \mathrm{mL}$. The results of analysis are shown in Fig. 3. No increase of 8-OHdG in DNA was detected with any irradiation time at any dose of TBZ, while $N$-nitrosopyrrolidine at $1 \mathrm{mg} / \mathrm{mL}$ used as a positive control caused 8-OHdG formation. The data suggest that UVA-treatment of TBZ does not generate oxidative damage in DNA, and 8-OHdG is not likely the mechanism responsible for the photomutagenesis of TBZ. We previously investigated inhibitory effects of several scavengers for reactive oxygen species such as ethanol, dimethyl sulfoxide, mannitol, histidine, ascorbic acid, and epigallocatechin on photomutagenic activation of TBZ and found that these scavengers did not show any apparent inhibitory effects. In addition, neither catalase nor SOD inhibited the photomutagenicity of TBZ in reverse mutation assays using E. coli WP2 


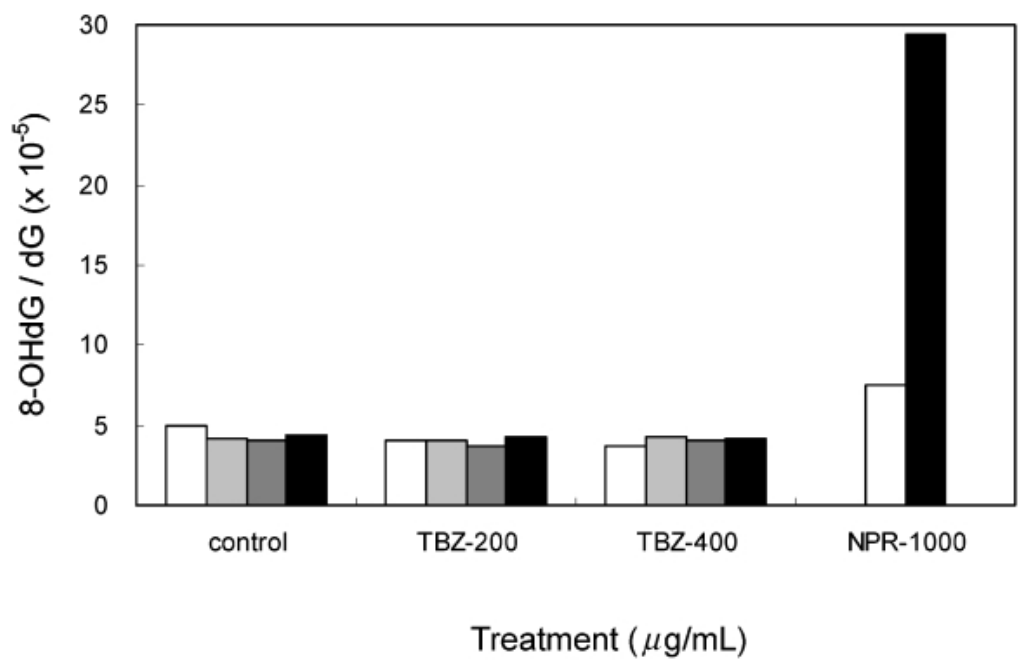

Fig. 3. 8-OHdG in DNA exposed to TBZ and UVA. UVA was irradiated for 15, 30, and 60 min on the mixture of DNA and TBZ (200 and 400 $\mu \mathrm{g} / \mathrm{mL}$ ) in phosphate buffer. Without UVA (white bar); UVA 15 min (light gray bar); UVA 30 min (dark gray bar); UVA 60 min (black bar). NPR $(N$-nitrosopyrrolidine, $1000 \mu \mathrm{g} / \mathrm{mL})$ was used as the positive control.

$u v r A /$ pKM101 (2). We also reported that TBZ with UVA irradiation caused $\mathrm{G}: \mathrm{C} \rightarrow \mathrm{A}: \mathrm{T}$ transitions most frequently, followed by $\mathrm{A}: \mathrm{T} \rightarrow \mathrm{T}: \mathrm{A}$ transversions and $\mathrm{A}: \mathrm{T} \rightarrow \mathrm{G}: \mathrm{C}$ transitions. However, induction of $\mathrm{G}: \mathrm{C} \rightarrow$ $\mathrm{T}:$ A transversions was very low (1). G:C $\rightarrow \mathrm{T}:$ A transversions are known to be typical mutations caused by oxidative DNA damage (18). Therefore, a different mechanism, perhaps direct interaction with DNA, must be involved in the photomutagenicity of UVA-irradiated TBZ. We suspect that the production of radicals followed by DNA bulky adduct formation is involved, but that awaits future investigation.

\section{References}

1 Watanabe-Akanuma M, Ohta T, Yamagata $H$. Photomutagenicity of thiabendazole, a postharvest fungicide, in bacterial assays. Environ Mol Mutagen. 2003; 41: 92-8.

2 Watanabe-Akanuma $\mathrm{M}$, Ohta $\mathrm{T}$. Inhibitory effects of $\mathrm{NADH} / \mathrm{NADPH}$ in S9mix on photo-mutagenicity of thiabendazole following UVA-irradiation in $E$. coli. Environ Mutagen Res. 2005; 27: 7-12.

3 Watanabe-Akanuma M, Ohta T, Sasaki YF. A novel genotoxic aspect of thiabendazole as a photomutagen in bacteria and cultured human cells. Toxicol Lett. 2005; 158: 213-9.

4 Schneider JE, Price S, Miadt L, Gutteridge JMC, Floy RA. Methylene blue plus light mediates 8-hydroxy 2'deoxyguanosine formation in DNA preferentially over strand breakage. Nucleic Acids Res. 1990; 18: 631-5.

5 Ciulla TA, Epling GA, Kochevar IE. Photoaddition of chlorpromazine to guanosine-5'-monophosphate. Photochem Photobiol. 1986; 43: 607-13.

6 Gocke E. Review of the genotoxic properties of chlorpromazine and related phenothiazines. Mutat Res. 1996; 366: 9-21.
7 Mauthe RJ, Cook VM, Coffing SL, Baird WM. Exposure of mammalian cell cultures to benzo[a]pyrene and light results in oxidative DNA damage as measured by 8-hydroxydeoxyguanosine formation. Carcinogenesis. 1995; 16: 133-7.

8 Fujiwara $\mathrm{M}$, Honda $\mathrm{Y}$, Inoue $\mathrm{H}$, Hayatsu $\mathrm{H}$, Arimoto S. Mutations and oxidative DNA damage in phage M13mp2 exposed to $N$-nitrosomorpholine plus near-ultraviolet light. Carcinogenesis. 1996; 17: 213-8.

9 Arimoto-Kobayashi S, Kaji K, Sweetman GM, Hayatsu $\mathrm{H}$. Mutation and formation of methyl- and hydroxylguanine adducts in DNA caused by $N$-nitrosodimethylamine and $N$-nitrosodiethylamine with UVA irradiation. Carcinogenesis. 1997;18: 2429-33.

10 Arimoto-Kobayashi S, Anma N, Yoshinaga Y, Douki T, Cadet J, Hayatsu H. Oxidative damage and induced mutations in m13mp2 phage DNA exposed to $N$ nitrosopyrrolidine with UVA radiation. Mutagenesis. 2000; 15: 473-7.

11 Arimoto-Kobayashi S, Ando Y, Horai Y, Okamoto K, Hayatsu H, Lowe JE, Green MH. Mutation, DNA strand cleavage and nitric oxide formation caused by $\mathrm{N}$ nitrosoproline with sunlight: a possible mechanism of UVA carcinogenicity. Carcinogenesis 2002; 23: 1537-40.

12 Maron D, Ames BN. Revised methods for the Salmonella mutagenicity test. Mutat Res. 1983; 113: 173-215.

13 Venturini S, Tamaro M, Monti-Bragadin C, Bordin F, Baccicchetti F, Carlassare F. Comparative mutagenicity of linear and angular furocoumarins in Escherichia coli strains deficient in known repair functions. Chem Biol Interact. 1980; 30: 203-7.

14 Federal Register. Sunscreen Drug Products for Over-theCounter Human Use. final monograph. 1999; 64: 27666-91.

15 Martindale. The Extra Pharmacopenia. 31st ed. Reynolds JEF, editor. Royal Pharmacopenia Society (London): 1999; 1562. 
16 Inbaraj JJ, Bilski P, Chignell CF. Photophysical and photochemical studies 2-phenylbenzimidazole and UVB sunscreen 2-phenyibenzimidazole-5-sulfonic acid. Photochem Photobiol. 2002; 75: 107-16.

17 Stevenson C, Davies RJH. Photosensitization of guaninespecific DNA damage by 2-phenylbenzimidazole and the sunscreen agent 2-phenylbenzimidazole-5-sulfonic acid. Chem Res Toxicol. 1999; 12: 38-45.

18 Cheng KC, Cahill DS, Kasai H, Nishimura S, Loeb LA. 8-Hydroxyguanine, an abundant form of oxidative DNA damage, causes $\mathrm{G} \rightarrow \mathrm{T}$ and $\mathrm{A} \rightarrow \mathrm{C}$ substitutions. J Biol Chem. 1992; 267: 166-72. 